\title{
Pemetaan Jenis, Indikator dan Kegunaan Kepemimpinan Pendidikan: Kajian Literatur dari Situs Indonesian Publication Index (IPI)
}

\author{
Rais Hidayat \\ Universitas Pakuan \\ rais72rais@gmail.com, rais.hidayat@unpak.ac.id \\ Yuyun Elizabeth Patras \\ Universitas Pakuan \\ yuyunpatras64@gmail.com
}

\begin{abstract}
The site of Indonesian Publication Index (IPI) has become a benchmark and reference research in Indonesia. The purpose of this research is to map educational leadership articles on IPI sites based on types, indicators, and usefulness of educational leadership. This research method used literatur study, where researchers examined 91 scientific articles sourced from the corpus of the IPI database, researchers do the sorting and analysis and then the data communicated through descriptive statistics. The findings of this research are as follows: (1) types of educational leadership research methods include qualitative and quantitative methods, but the types of mixed methods are rarely found; (2) types of publicized educational leadership research are in accordance with existing educational leadership theories, but Indonesia has several characteristics of educational leaders such as boarding school leadership; (3) researchers in Indonesia have used indicators of effective educational leadership in accordance with what researchers use in other countries; and (4) education leadership researchers in Indonesia have provided recommendations for improving educational leadership. The above findings are expected to be discussed in developing educational leadership research in Indonesia.
\end{abstract}

Keywords: Educational Leadership, Indicators of Educational Leadership, Types of Educational Leadership

\section{Article Info}

Received date: 10 Oktober $2018 \quad$ Revised date: 15 Desember $2018 \quad$ Accepted date: 24 Desember 2018

\section{PENDAHULUAN}

Peran pemimpin pada lembaga pendidikan sangat strategis (Spillane, 2003). Pada posisi tersebut melekat kekuasaan dan wewenang untuk digunakan secara efektif dalam memengaruhi jalannya lembaga pendidikan (Hallinger, 2007). Tidak ada guru yang gagal, yang ada adalah kepala sekolah yang tidak bisa memimpin. Kemajuan suatu lembaga pendidikan bergantung pada upaya pemimpinnya dalam menggerakan mesin organisasi (Peleg, 2012). Tidak ada sekolah yang maju tanpa peran pimpinan (Connelly, 2013).

Pemimpin sekolah memengaruhi kinerja anggota sekolah (Bush, 2007), yaitu para guru dan staf pegawai lainnya agar bekerja lebih maksimal, menampilkan etos kerja tinggi, dan secara sukarela bekerjasama dengan anggota lainnya untuk mewujudkan standar mutu yang diharapkan oleh konsumen pendidikan, masyarakat dan pemerintah 
(Hallinger \& Walker, 2017). Perilaku kepemimpinan memprediksi kinerja (Linda Bendikson, Viviane Robinson, 2012). Kepemimpinan adalah faktor kunci dalam perubahan yang berhasil (Holsted, 2016).

Posisi strategis kepemimpinan pendidikan dan perannya pada lembaga pendidikan telah menarik minat para peneliti (Bush, 2007); Sumintono, 2010). Terdapat sejumlah dan berbagai jenis penelitian kepemimpinan pendidikan yang sudah dipublikasikan dalam bentuk cetak maupun elektronik. Bahkan sekarang muncul istilah eleadership dalam pendidikan untuk menunjukan adanya perkembangan bahwa kepemimpinan itu sangat penting dan terus diteliti (Oh Siew Pei, 2018).

Penelitian terhadap kepemimpinan pendidikan berkembang pesat di Indonesia. Hal ini wajar karena Indonesia merupakan negara yang paling luas di wilayah Asia Tenggara (Sticher, 2014). Indonesia sebagain besar wilayahnya adalah lautan sehingga Indonesia dikenal sebagai negara kepulauan (Tumonggor et al., 2013). Penduduk Indonesia terdiri dari berbagai macam suku bangsa dan beraneka ragam bahasa (Siregar, 2016). Wilayah yang luas dan beraneka suku bangsa menyebabkan Indonesia kaya dengan perbedaan namun tetap bersatu (Samuel Bazzi, Arya Gaduh, Alexander Rothenberg, 2017). Indonesia terus membangun masyarakatnya sekaligus terus mengupayakan berbagai penelitian, termasuk penelitian pendidikan (Inaya Rakhmani, 2016) dan penelitian tentang kepemimpinan pendidikan.

Penelitian di Indonesia kini terhimpun dalam situs Indonesian Publication Index (IPI) dengan alamat situs http://id.portalgaruda.org/. Mulai tanggal 4 Juli 2018 IPI telah diakuisisi oleh Kementerian Riset Teknologi dan Pendidikan Tinggi (RISTEKDIKTI) yang kemudian sekarang disebut GARUDA atau Garba Rujukan Digital dengan alamat situs http://garuda.ristekdikti.go.id. sekarang menjadi sumber rujukan atas publikasi ilmiah. GARUDA merupakan basis data yang komprehensif yang mencakup berbagai bidang keilmuan.

Sampai Juli 2018, IPI memiliki 595,647 artikel dan 5,064 jurnal. Jika menggunakan keyword: kepemimpinan pendidikan (educational leadership) untuk mencari artikel, maka akan ditemukan ratusan artikel yang membahas kepemimpinan pendidikan. Selama ini belum ada penelitian yang memetakan tentang hasil publikasi tentang kepemimpinan pendidikan yang berasal dari situs IPI. Artikel ini akan mendeskripsikan kepemimpinan pendidikan berdasarkan jenis kepemimpinan, indikator kepemimpinan yang efektif, dan kegunaan penelitian kepemimpinan pendidikan.

\section{Jenis Kepemimpinan Pendidikan}

Jenis kepemimpinan adalah hubungan di mana satu orang mengarahkan, mengkoordinasi dan mengawasi yang lain untuk mencapai tujuan bersama (Muhammad Saqib Khan \& Irfanullah Khan, Qamar Afaq Qureshi, Hafiz Muhammad Ismail, Hamid Rauf, Muhammad Tahir, 2015). Kepemimpinan menempati posisi puncak dalam organisasi yang mampu menggerakan organisasi dan mencapai tujuan organisasi (Spillane, 2003).

Jenis kepemimpinan adalah hal-hal yang terlihat dipraktekkan oleh seorang pemimpin seperti mengarahkan, mengubah dan transaksi (Yahya, 2015). Jenis kepemimpinan sangat berragam. Pada dunia pendidikan kepemimpinan pendidikan berubah dari jenis 'educational administration' menjadi 'educational management' dan kini mengarah ke 'educational leadership' (Adams, 2017). Berbagai jenis kepemimpinan di dalam organisasi pendidikan dipengaruhi oleh latar belakang si pemimpin dan keadaan sekolah (Urick \& Bowers, 2014). Hallinger \& Murphy and Robinson menggunakan istilah 
Kelola: Jurnal Manajemen Pendidikan, Vol. 5, No. 2, Juli-Desember 2018

instructional leadership untuk menyebut kepemimpinan di sekolah (Velarde, 2017).

Terdadapat beberapa tipe kepemimpinan di sekolah yang harus diintegrasikan antara lain transformational, transactional, inspirational, and instructional leadership (Smith \& Squires, 2016). Tipe kepemimpinan lainnya democratic leadership, authoritarian style dan laissez-faire leadership styles (Yahya, 2015). Terdapat pula istilah tipe kepemimpinan authentic leadership (Men, 2012) dan e-leadership (Oh Siew Pei, 2018).

Jenis kepemimpinan (type of leadership) seringkali disamakan atau dipertukarkan dengan gaya kepemimpinan (leadership style) (Urick \& Bowers, 2014). Jenis kepemimpinan antara lain The Charismatic Leader, Transformational Leaders and Transactional Leaders (Evans-Curtis, 2004). Macam-macam kepemimpinan terdiri dari the Great Man theory, Trait theory, Process leadership theory, Style and Behavioral theory, Transformational, Transactional and Laissez Faire leadership theory (Zakeer Ahmed Khan, Allah Nawaz, 2016).

\section{Indikator Kepemimpinan Efektif}

Indikator adalah metrik yang bermakna, sederhana, dan dapat dikuantifikasi yang digunakan untuk menilai kemajuan menuju pencapaian target (Suter, 2015). Bagaimanakah mengevaluasi bahwa tujuan telah tercapai? Indikator yang dibuat dengan benar dapat memberikan jawaban yang benar (Network, 2015). Indikator kepemimpinan pendidikan efektif dalam pada artikel ini diartikan sebagai ciri-ciri atau parameter atau ukuran yang digunakan peneliti untuk mengukur keefektifan atau kinerja dari sebuah kepemimpinan dalam lembaga pendidikan.

Beberapa ciri kepemimpinan pendidikan efektif adalah pemimpin sekolah mampu menyesuaikan program pengajaran dengan kebutuhan sekolah, mempromosikan kerja tim di antara guru, dan terlibat dalam pemantauan, evaluasi dan pengembangan profesional guru (Andreas Schleicher, 2013). Kepemimpinan pendidikan yang efektif adalah pemimpin yang melakukan hubungan personal dalam mengarahkan, mengorganisir, mengkoordinir dan mengawasi bawahan untuk mencapai tujuan bersama (Muhammad Saqib Khan \& Irfanullah Khan, Qamar Afaq Qureshi, Hafiz Muhammad Ismail, Hamid Rauf, Muhammad Tahir, 2015).

Kepemimpinan pendidikan yang efektif yaitu mampu memberikan visi ke depan (visionary), memiliki gairah dan semangat yang tinggi (passionate), kreatif, fleksibel, menginspirasi, inovatif, berani, dan mengeksperimen imajinasi untuk memulai perubahan (Amanchukwu, Stanley, \& Ololube, 2015). Kepala sekolah yang efektif memiliki kemampuan sebagai berikut: Rational, Consulting Persistent, Problem solving Toughminded, Analytical Structured Deliberate, Authoritative Stabilising (Amanchukwu et al., 2015).

\section{Kegunaan Kepemipinan Pendidikan}

Kepemimpinan pendidikan yang tinggi berpengaruh pada keberhasilan memotivasi karyawannya untuk menunjukkan kinerja yang tinggi (Susanthi \& Setiawan, 2014). Kepemimpinan dapat mempengaruhi kinerja dan produktivitas karyawan (Nanjundeswaras \& Swamy, 2014). Kepemimpinan berguna untuk ketercapaian tujuan organisasi (Holsted, 2016)(Linda Bendikson, Viviane Robinson, 2012), meningkatkan kinerja guru dan karyawan sekolah (Hallinger \& Huber, 2012), mempercepat transformasi organisasi (Joseph, 1986) (Hallinger, 2003) (Adams \& Zabidi, 2017), meningkatkan mutu pendidikan di sekolah (Donna, 2011).

Kepemimpinan pendidikan yang baik dapat meningkatkan konsistensi atau kedisiplinan karyawan (Amanchukwu et al., 2015); Muhammad Saqib Khan \& Irfanullah Khan, Qamar Afaq Qureshi, Hafiz Muhammad Ismail, Hamid Rauf, Muhammad Tahir, 2015), 
meningkatkan mutu pelayanan guru (Atkinson, 2014), menjaga dan meningkatkan komitmen guru dan karyawan (Oh Siew Pei, 2018)(Hallinger, 2003), memperbaiki keprofesionalan guru (Heck \& Hallinger, 2005)(Eyal \& Roth, 2010), bahkan kepemimpinan pendidikan dapat meningkatkan hasil belajar walaupun secara tidak langsungf (Heck \& Hallinger, 2005)(Hallinger \& Heck, 2010).

Kepemimpinan pendidikan juga berguna untuk meningkatkan kolaborasi, mewujudkan visi, tujuan, dan target sekolah, mencapai kesetaraan dan keunggulan, memastikan lingkungan yang tertib, mendukung, dan kondusif untuk pembelajaran dan kesejahteraan siswa, meningkatkan pembuatan perencanaan yang efektif, koordinasi dan evaluasi kurikulum, meningkatkan promosi, membangun kapasitas kolektif untuk melakukan evaluasi dan peningkatan berkelanjutan (Holsted, 2016).

\section{METODE PENELITIAN}

Tujuan dari penelitian ini adalah untuk mendeskripsikan tentang kondisi publikasi penelitian tentang kepemimpinan pendidikan yang ada di Indonesia. Penelitian ini menggunakan kajian literatur yang dipublikasikan pada situs Indonesian Publication Index (IPI). Kata kunci yang digunakan untuk mendapatkan artikel adalah "kepemimpinan pendidikan". Artikel yang digunakan untuk diteliti berasal dari kurun waktu antara 2002 samapi 2018. Adapun pencarian artikel dibatasi sampai April 2018.

Penelitian ini menggunakan kajian literatur dengan tiga langkah utama yaitu: (1) eksplorasi artikel ilmiah; (2) Interpretasi data; dan (3) komunikasi (Flick, 2013)(Cronin, Ryan, \& Coughlan, 2008). Proses lebih detail penelitian ini mencakup tahap-tahap berikut: (1) masuk ke laman IPI dan mengetikan kata kunci "kepemimpinan pendidikan"; mengumpulkan dan memeriksa artikel ilmiah;
(3) menganalisis artikel tentang kepemimpinan pendidikan sesuai persyaratan minimal, yaitu: tema tentang kepemimpinan, nama penulis, nama jurnal, penerbit, volume dan nomor jurnal. Berdasarkan kriteria tersebut didapatkan sebanyak 91 artikel ilmiah (appendix 1); (4) peneliti melakukan pemilahan, analisis dan interpretasi data, dan (5) melakukan laporan penelitian atau komunikasi data.

Perumusan masalah dalam penelitian ini sebagai berikut: (1) Jenis penelitian apakah yang digunakan dalam penelitian kepemimpinan pendidikan di Indonesia?; (2) Jenis-jenis kepemimpinan pendidikan apa yang diteliti dan dipublikasikan di Indonesia?; (3) Indikator-indikator apa yang digunakan para peneliti untuk mengukur kepemimpinan pendidikan yang efektif? ; (4) Kegunaan apa yang diharapkan dari hasil-hasil penelitian kepemimpinan pendidikan di Indonesia?

\section{HASIL PENELITIAN DAN PEMBAHASAN}

\section{Hasil Penelitian}

\section{Jenis Penelitian Kepemimpinan Pendidikan}

Jenis metode dan desain penelitian tentang kepemimpinan pendidikan di Indonesia yang digunakan adalah kualitatif dan kuantitatif. Jumlah penelitian kualitatif lebih banyak daripada penelitian kuantitatif. Sedangkan penelitian yang menggunakan mixed-method atau menggabungkan penelitian kualitatif dan kuantitatif belum popular dalam penelitian kepemimpinan pendidikan.

Beberapa contoh penelitian berjenis kualitatif antara lain: Peranan Kepemimpinan Kepala Sekolah (Ason, 2013), Kepemimpinan Pendidikan di sekolah (Nasution, 2015), dan Kepemimpinan Pendidikan Untuk Mengembangkan Sekolah Bermutu (Sermal, 2015). Contoh penelitian berjenis kuantitatif antara lain: Pengaruh Kepemimpinan Kepala Sekolah, Supervisi Dan Kepuasan Kerja Guru Terhadap Kinerja (Walukow, Donald M. F. 
Tiogas, 2014), Pengaruh Kepemimpinan Kepala Sekolah, Iklim Kinerja Guru Terhadap Mutu Pendidikan (Agustina, Sulton Djasmi, 2014), dan Hubungan Perilaku Kepemimpinan Kepala Sekolah Dan Kemampuan Mengajar Guru Dengan Inovasi Pendidikan (Sumarsono, 2012).Penelitian kepemimpinan pendidikan dengan metode kualitatif didominasi oleh kajian literatur, dimana si peneliti hanya mengumpulkan konsep atau teori tentang kepemimpinan pendidikan kemudian ditarik sebuah kesimpulan untuk diaplikasikan dalam dunia pendidikan. Contoh penelitian yang hanya menggunakan kajian literatur tentang kepemimpinan pendidikan antara lain: Kepemimpinan Pendidikan (Rohmat, 2006), Kepemimpinan Kepala Sekolah Yang Efektif Kunci Pencapaian Kualitas Pendidikan (Ekosiswoyo, 2007) dan Agama Membentuk Kepribadian Dan Gaya Kepemimpinan Pendidikan (Nujuludin, 2013)

Tabel 1. Jenis Metode Penelitian Kepemimpinan Pendidikan

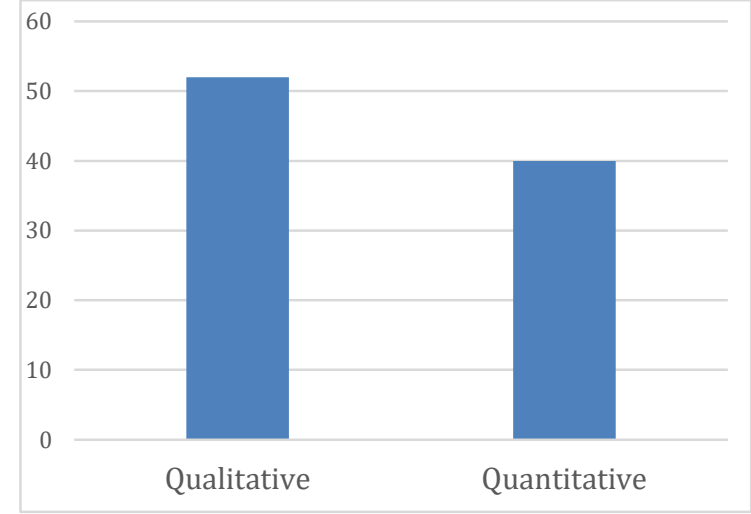

Secara umum kajian literatur tentang kepemimpinan pendidikan di Indonesia meliputi unsur sebagai berikut: hakikat atau definisi kepemimpinan, fungsi dan tugas pemimpin, ciri-ciri kepemimpinan yang efektif, pengembangan kepemimpinan dan bagaimana kepemimpinan dapat dilaksanakan di sekolah dengan baik.

Sedangkan penelitian dengan pendekatan kuantitatif didominasi oleh penelitian korelasi, dimana peneliti melakukan pengujian hipotesis untuk menghubungkan kepemimpinan pendidikan dangan variabel terikat seperti produktivitas, kinerja dan keinovatifan guru. Beberapa contoh penelitian tentang kepemimpinan pendidikan yang menggunakan pendekatan kuantitatif melalui desain korelasional antara lain: Pengaruh Kepemimpinan Kepala Madrasah dan Supervisi Pengawas Madrasah terhadap Kinerja Guru untuk Mewujudkan Mutu (Ruhiyat, 2017), Pengaruh Kepemimpinan

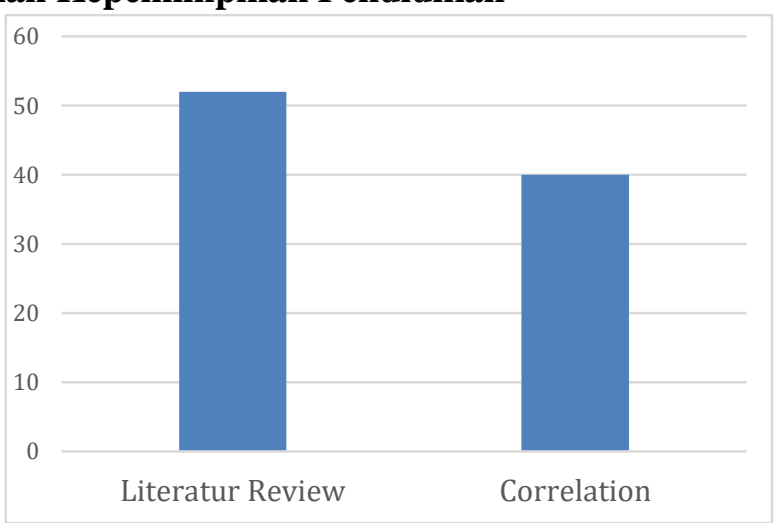

Transformasional dan Lingkungan Kerja Terhadap Semangat Kerja Tenaga Kependidikan (Ratnasari \& Sutjahjo, 2017) dan Pengaruh Gaya Kepemimpinan Transformasional Terhadapmotivasi Kerja Pegawai (Arwin Sanjaya, 2014).

Secara umum penelitian kepemimpinan yang menggunakan pendekatan kualitatif hanya mengkaji tidak lebih dari 2 variabel yaitu kepemimpinan dan implikasinya pada dunia pendidikan, contohnya seperti: Kepemimpinan Pendidikan Untuk Mengembangkan Sekolah Bermutu (Sermal, 2015). Tidak ada pengujian hipotesis dalam penelitian kualitatif tersebut.

Sedangkan penelitian dengan pendekatan kuantitatif paling sedikit dengan 2 variabel. Penelitian dengan jenis tersebut mengkorelasikan kepemimpinan dan variabel lain dengan salah satu variabel terikat. Contoh penelitian korelasional yang menghubungkan kepemimpinan bersama variabel lain terhadap variabel terikat antara lain: Pengaruh 
Kepemimpinan, Motivasi, Dan Lingkungan Kerja Terhadap Kinerja Pegawai Badan Kepegawaian Pendidikan Dan Pelatihan (Hardiyana \& Helwiyan, 2011) dan Hubungan Perilaku Kepemimpinan Kepala Sekolah Dan Kemampuan Mengajar Guru Dengan Inovasi Pendidikan (Sumarsono, 2012).

Dalam penelitian kuantitatif, secara umum variabel kepemimpinan pendidikan merupakakan variabel yang memengaruhi variabel terikat antara lain motivasi kerja, kinerja guru, dan produktivitas guru. Secara umum temuan penelitian di Indonesia menunjukkan adanya hubungan positif yang signifikan antara kepemimpinan dengan variabel yang dipengaruhinya seperti kinerja guru dan komitmen pada organisasi.

Tabel 2. Metode Penelitian dan Variabel

\begin{tabular}{ccccccc}
\hline & & $\begin{array}{c}\text { One } \\
\text { Variabel }\end{array}$ & $\begin{array}{c}\text { Two } \\
\text { Variabels }\end{array}$ & $\begin{array}{c}\text { Three } \\
\text { Variabels }\end{array}$ & $\begin{array}{c}\text { Four } \\
\text { Variabels }\end{array}$ & Jumlah \\
\hline \multirow{2}{*}{ Method } & Qualitative & 13 & 35 & 3 & 0 & 51 \\
\cline { 2 - 7 } & Quantitative & 2 & 8 & 17 & 13 & 40 \\
\hline \multicolumn{2}{c}{ Total } & 15 & 43 & 20 & 13 & 91 \\
\hline
\end{tabular}

Adapun publikasi artikel penelitian tentang kepemimpinan pendidikan paling banyak dipublikasikan antara tahun 2012 sampai 2015.

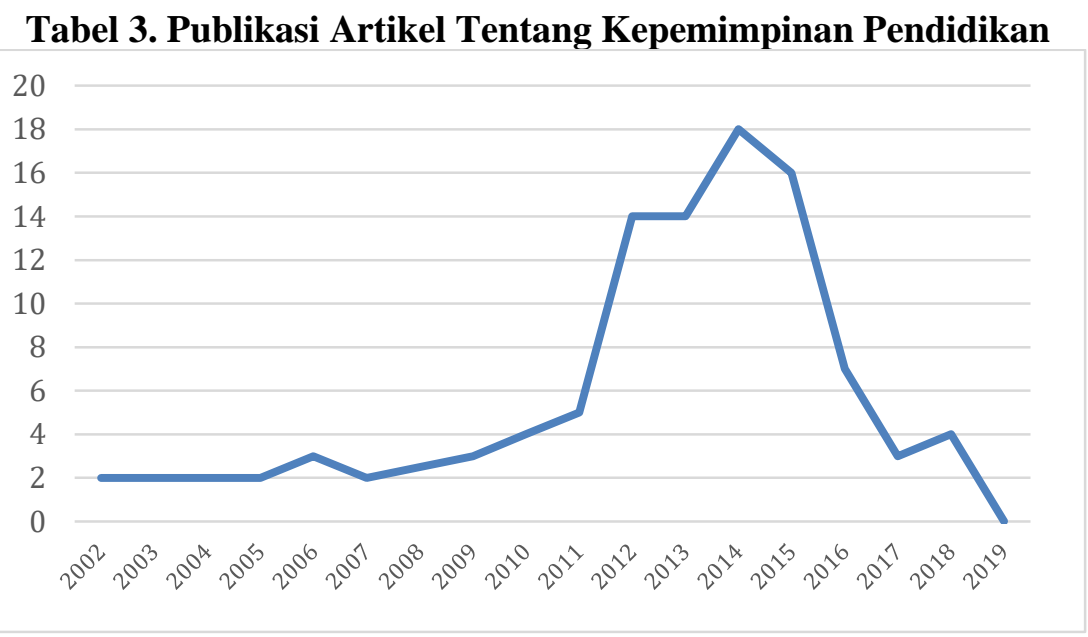

\section{Jenis Kepemimpinan Pendidikan}

Jenis kepemimpinan pendidikan yang menempati posisi paling banyak dipublikasikan yaitu gaya kepemimpinan (leadership style), kepemimpinan kepala sekolah (principal leadership) dan kepemimpinan pendidikan (educational leadership).

Gaya kepemimpinan mengacu pada bagaimana seorang pemimpin menggunakan gaya khasnya untuk mencapai tujuan yang dia kehendaki. Contoh penelitian tentang gaya kepemimpinan antara lain: Pengaruh Gaya Kepemimpinan Transformasional Terhadap Motivasi Kerja Pegawai Pada Kantor Lembaga
Penjamin Mutu Pendidikan (Arwin Sanjaya, 2014) dan Pengaruh Gaya Kepemimpinan Kepala Sekolah Dan Motivasi Berprestasi Guru Terhadap Layanan Pendidikan Di Sekolah Menengah Atas (Deki Wibowo, 2014).

Kepemimpinan kepala sekolah menunjuk pada penyebutan sosok yang menjadi pemimpin di lembaga atau organisasi pendidikan. Contoh penelitian tentang kepemimpinan kepala sekolah antara lain: Pengaruh Kepemimpinan Transformasional Kepala Sekolah, Pelaksanaan MBS, dan Pelaksanaan TU Terhadap Kualitas Pendidikan SD/MI Depok, Sleman (Wahyudi, 2014) dan 
Kelola: Jurnal Manajemen Pendidikan, Vol. 5, No. 2, Juli-Desember 2018

Pengaruh Kepemimpinan Kepala Sekolah, Supervisi Dan Kepuasan Kerja Guru Terhadap Kinerja Guru MIPA di Yayasan Pendidikan Advent Timika (Walukow, Donald M. F. Tiogas, 2014)

Sedangkan kepemimpinan pendidikan memimpin lembaga pendidikan. Contoh penelitian tentang educational leadership antara lain: Kepemimpinan Pendidikan Di Sekolah (Nasution, 2015) dan Manajemen dan Kepemimpinan Pendidikan Islam (Karimah, 2015)

merujuk pada peran seorang pemimimpin yang

Tabel 4. Jenis Kepemimpinan Pendidikan

\begin{tabular}{|c|c|c|}
\hline Type of Leadership & Articles & $\%$ \\
\hline Gaya Kepemimpinan (Leadership Style) & 26 & 28.6 \\
\hline Kepemimpinan Kepala Sekolah (Principal Leadership) & 20 & 22.0 \\
\hline Kepemimpinan Pendidikan (Educational Leadership) & 12 & 13.2 \\
\hline Kepemimpinan Transformasional (Transformational Leadership) & 9 & 9.9 \\
\hline Kepemimpinan Pesantren (Boarding School Leadership) & 5 & 5.5 \\
\hline Kepemimpinan Islam (Islamic Educational Leadership) & 5 & 5.5 \\
\hline Kepemimpinan Nabi (Prophetic Leadership) & 3 & 3.3 \\
\hline Perilaku Kepemimpinan (Leadership Behavior) & 3 & 3.3 \\
\hline Kepemimpinan Partisipatif (Participative Leadership) & 1 & 1.1 \\
\hline Kepemimpinan Istruksional (Instructional Leadership) & 1 & 1.1 \\
\hline Kepemimpinan Melayani (Servant Leadership) & 1 & 1.1 \\
\hline Lainnya & 5 & 5.5 \\
\hline Jumlah & 91 & 100 \\
\hline
\end{tabular}

Adapun yang masih sedikit diteliti antara lain tentang participative leadership, servant leadership, dan instructional leadership. Partisipatif leadership mengacu pada kemampuan seorang pemimpin untuk melibatkan anggotanya dalam mencapai tujuan organisasi. Servant leadership mengacu kepada kehendak dari pemimpin untuk melayani dengan sepenuh hati untuk mencapai tujuan organisasi. Sedangkan instructional leadership mengacu kepada bagaimana upaya seorang kepala sekolah dalam mengarahkan para guru untuk mencapai target sekolah, khususnya dalam bidang akademik.

Sedangkan yang masuk katagori ciri khas Indonesia antara lain: Kepemipinan Pendidikan Natsir (Saiful Falah, 2015) , Kepemimpinan Pesantren (Sagala, 2016), Kepemimpinan Islam (Subhan, 2013), Kepemimpinan Nabi (Arifin, 2016) dan Kepemimpinan Karakter (Usman, 2013).

Kepemipinan pendidikan Natsir mengacu kepada pemikiran dan perilaku tokoh kemerdekaan dan muslim Indonesia dalam memimpin dan memengaruhi lembaga pendidikan (Saiful Falah, 2015). Kepemimpinan pesantren mengacu kepada sosok pengasuh dan pemimpin pesantren (Sagala, 2016). Kepemipinan Nabi mengacu kepada pemikiran dan ajaran seorang Nabi (Arifin, 2016). Sedangkan Kepemimpinan karakter mengacu pada sosok ideal dengan ciriciri tertentu yang diharapkan menjadi pemimpin-pemimpin Indonesia (Usman, 2013).

\section{Indikator Kepemimpinan yang Efektif}

Peneliti mengambil 2 sampai 4 indikator yang merujuk sebuah kepemimpinan pendidikan yang efektif. Dari 91 artikel yang dianalisis, terdapat 341 kata atau frase yang merujuk pada indikator kepemimpinan yang efektif. Kemudian dari 341 kata atau frase tersebut dilakukan pengkodingan berdasarkan kesamaan kata atau kesamaan makna kata/frase. 
Tabel 5. Indikator Kepemimpinan Pendidikan

\begin{tabular}{lcc}
\hline \multicolumn{1}{c}{ Indicators } & Total & \% \\
\hline Mengelola (Managing) & 33 & 10 \\
\hline Melakukan perubahan (Transform) & 30 & 9 \\
\hline Merngorganisir (Organizing) & 29 & 9 \\
\hline Komunikasi (Communicating) & 28 & 8 \\
\hline Memengaruhi (Influencing) & 26 & 8 \\
\hline Membimbing (Guiding) & 23 & 7 \\
\hline Berpartisipasi (Participating) & 22 & 6 \\
\hline Memiliki visi, misi (Vision) & 20 & 6 \\
\hline Menjadi contoh (Role Model) & 18 & 5 \\
\hline Memotivasi (Motivating) & 17 & 5 \\
\hline Merencanakan (Planning) & 14 & 4 \\
\hline Demokratis (Democratic) & 13 & 4 \\
\hline Dipercaya (Trust) & 12 & 4 \\
\hline Melakukan supervisi (Supervision) & 12 & 4 \\
\hline Memahami situasi (Situational) & 11 & 3 \\
\hline Berwibawa (Charismatic) & 10 & 3 \\
\hline Mencintai (Love) & 5 & 1 \\
\hline Pengambil keputusan (Decision Making) & 5 & 1 \\
\hline Mendelegasikan (Delegation) & 4 & 1 \\
\hline Otoriter (Autocratic) & 3 & 1 \\
\hline Regenerasi (Regeneration) & 2 & 1 \\
\hline Transaksi (Transactional) & 2 & 1 \\
\hline Kolektif (Collective) & 1 & 0 \\
\hline Bebas (Laissez faire) & 1 & 0 \\
\hline \multicolumn{1}{c}{ Jumlah } & 341 & 100 \\
\hline & &
\end{tabular}

Berdasarkan data di atas dapat dinyatakan bahwa 5 indikator terbanyak pertama yang digunakan oleh para peneliti kepemimpinan pendidikan di Indonesia yaitu: Managing, Transforming, Organizing, Communicating dan Influencing. 5 indikator terbanyak kedua yaitu: Guiding, Participating, Vision, Role Model, Motivating. Sedangkan 5 indikator terbanyak ketiga yaitu: Planning, Democratic, Trust, Supervision, dan Situational.

Temuan atas indikator kepemimpinan yang efektif sejalan temuan para peneliti lain, yaitu: kemampuan mengelola (Lemay \& Ellis, 2008)(Memon, Simkins, \& Sisum, 2006)Nikoloski, 2015), kemampuan melakukan perubahan (Hallinger, 2007), kemampuan mengorganisir (Nanjundeswaras \& Swamy, 2014), kemampuan berkomunikasi
(Velarde, 2017, Nedelcu, 2013) dan kemampuan memengaruhi (Muhammad Saqib Khan \& Irfanullah Khan, Qamar Afaq Qureshi, Hafiz Muhammad Ismail, Hamid Rauf, Muhammad Tahir, 2015, Veliu, Manxhari, Demiri, \& Jahaj, 2017). Ini menunjukan bahwa indikator-indikator yang relevan sudah banyak digunakan dalam penelitian di negara-negara lain.

\section{Kegunaan Kepemimpinan Pendidikan}

Peneliti mengambil 2 sampai 4 indikator yang merujuk pada kegunaan praktis kepemimpinan pendidikan. Dari 91 artikel yang dianalisis, terdapat 232 kata atau frase yang merujuk pada kegunaan penelitian kepemipinan. Kemudian dari 232 kata atau frase tersebut dilakukan pengkodingan berdasarkan kesamaan kata atau kesamaan makna kata/frase. 
Kelola: Jurnal Manajemen Pendidikan, Vol. 5, No. 2, Juli-Desember 2018

Tabel 6. Kegunaan Kepemimpinan Pendidikan

\begin{tabular}{lcc}
\hline \multicolumn{1}{c}{ Kegunaan Kepemimpinan } & Jumlah & \% \\
\hline Ketercapaian tujuan organisasi (Organizational Goal) & 52 & 22 \\
\hline Meningkatkan kijerja (Performance) & 33 & 14 \\
\hline Melakukan perubahan dalam organisasi (Transforming) & 29 & 13 \\
\hline Meningkatkan kualitas pendidikan (Education Quality) & 27 & 12 \\
\hline Memotivasi karyawan (Motivating People) & 25 & 11 \\
\hline Tercipta konsistensi (Consistentcy) & 12 & 5 \\
\hline Meningkatkan pelayanan (Educational Services) & 8 & 3 \\
\hline Meningkatkan komitmen (Commitment) & 8 & 3 \\
\hline Memperbaiki profesionalisme (Teacher Professionalism) & 7 & 3 \\
\hline Meningkatkan hasil belajar (Student Learning) & 6 & 3 \\
\hline Memperbaiki budaya organisasi (Organizational Culture) & 6 & 3 \\
\hline Meningkatkan kreatifitas (Creativity) & 3 & 1 \\
\hline Meningkatkan kepuasan kerja (Work Satisfaction) & 3 & 1 \\
\hline Meningkatkan prestasi (Achievement) & 3 & 1 \\
\hline Meningkatkan keinovatifan (Innovation) & 2 & 1 \\
\hline MenImproving facilities & 2 & 1 \\
\hline Improving Infrastructure & 2 & 1 \\
\hline Lainnya & 4 & 2 \\
\hline & 232 & 100 \\
\hline
\end{tabular}

Berdasarkan 232 pernyataan tentang kegunaan kepemimpinan pendidikan, terdapat 5 kata atau frase terbanyak pertama yaitu: Organizational Goal di tingkat pertama, meningkatkan kinerja organisasi peringkat kedua dan membuat perubahan pada peringkat ketiga.

Berdasarkan temuan tersebut, kegunaan kepemimpinan pendidikan di Indonesia sudah sejalan dengan hasil penelitian pendidikan di Negara-negara lain. Intinya kepemimpinan dalam institusi pendidikan berguna untuk ketercapaian tujuan pendidikan (Holsted,
2016)(Linda Bendikson, Viviane Robinson, 2012), peningkatan kinerja guru (Hallinger \& Huber, 2012), dan melakukan perubahan (Joseph, 1986) (Hallinger, 2003) (Adams \& Zabidi, 2017), peningkatan kualitas pendidikan (Donna, 2011), dan meningkatkan motivasi kerja (Hallinger \& Heck, 2010)(Hallinger \& Huber, 2012).

Berdasarkan kajian literatur di atas dapat diperoleh sebuah model kepemimpinan pendidikaan yang ada di Indonesia sebagai gambar berikut:

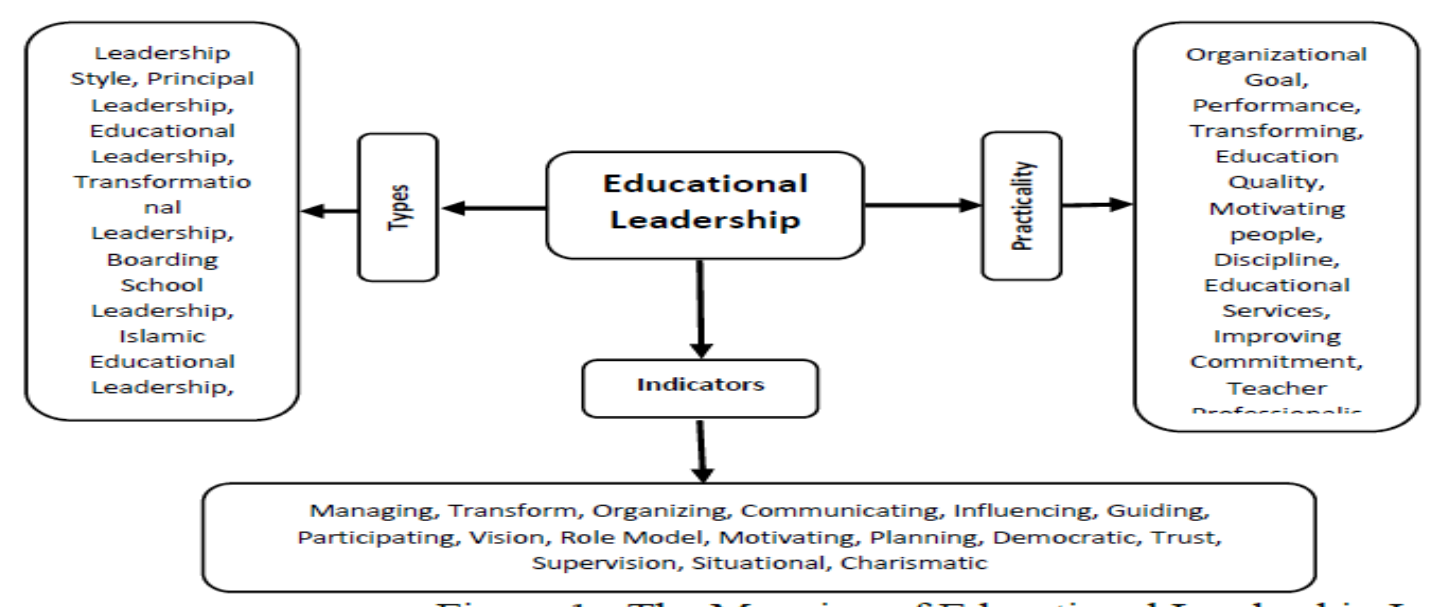

Figure 1: The Mapping of Educational Leadership In IPI 


\section{Pembahasan}

Jenis penelitian yang digunakan dalam penelitian kepemimpinan pendidikan di Indonesia masih didominasi oleh pendekatan kualitatif dan kuantitatif. Kedua pendekatan ini memiliki kelamahannya masing-masing (Atieno, 2009) sehingga perlu diperbaiki dengan meningkatkan kuantitas dan kualitas penelitian dengan menggunakan pendekatan mixed method (Ponce, 2015). Melalui pendekatan mixed method maka penelitian kepemimpinan pendidikan akan lebih banyak memberikan kontribusi untuk memperbaiki dan memberikan solusi bagi kemajuan pendidikan di Indonesia (Klette, 2012).

Gaya kepemimpinan merupakan jenis penelitian kepemipinan pendidikan yang paling banyak diteliti dan dipublikasikan. Hal ini relevan dengan penelitian selain di Indonesia seperti penelitian Smith dan Squires (2016) yang mengakui bahwa gaya kepemimpinan memainkan peran integral dalam hasil pendidikan yang positif dalam penciptaan budaya sekolah (Smith \& Squires, 2016), gaya kepemimpinan mempengaruhi kinerja dan produktivitas karyawan (Nanjundeswaras \& Swamy, 2014).

Jenis kepemimpinan pendidikan yang menjadi ciri khas Indonesia yaitu kepemimpinan yang berkembang sesuai lokalitas Indonesia. Jenis yang berorientasi pada lokalitas Indonesia mendasarkan diri pada keunikan lembaga pendidikan dan pengaruh kuatnya pengaruh pendidikan keagamaan di Indonesia sehingga melahirkan jenis kepemimpinan pendidikan yang berbeda, antara lain: kepemimpinan pesantren (Sagala, 2016, Ansor, 2014, Sulaiman, 2016), kepemimpinan Islam (Subhan, 2013, Karimah, 2015, Yusuf, 2014), kepemimpinan nabi (Arifin, 2016), kepemimpinan Natsir (Saiful Falah, 2015), dan kepemimpinan karakter (Usman, 2013).

Pengembangan kepemimpinan pendidikan yang berbasis lokalitas Indonesia sangat besar mengingat jumlah lembaga pendidikan berbasis lokalitas sangat besar (Zuhdi, 2015). Namun demikian pengembangan kepemimpinan pendidikan lokal harus diiringi dengan teori-teori kepemipinan pendidikan yang berkembang secara global. Hal tersebut perlu dilakukan agar kepemimpinan pendidikan Indonesia mampu mengembangkan multikulturalisme dan toleransi (Elihami, 2016)

Temuan penelitian ini menunjukkan bahwa peneliti kepemimpinan pendidikan di Indonesia sudah mampu memahami dan mengerti indikator kepemimpinan yang efektif seperti Managing, Transforming, Organizing, Communicating and Influencing. Fakta ini menunjukan bahwa peneliti di Indonesia sudah memahami variabel penelitian dengan baik. Namun demikian pembuatan indikator kepemimpinan pendidikan yang efektif masih harus terus ditingkatkan, misalnya dengan mengkombinasi antara teori global dan local.

Penelitian ini menunjukkan bahwa penelitian tentang kepemimpinan pendidikan sangat berguna. Rekomendasi untuk melakukan perbaikan kepemimpinan pendidikan sudah banyak dilakukan oleh para peneliti. Persoalannya adalah kualitas pendidikan Indonesia masih menghadapi tantangan besar (Suratno, 2016) walau pemerintah terus melakukan perubahan-perubahan dan memfasilitasi internasionalisasi pendidikan (Soejatminah, 2009), namun mentalitas dan komitmen yang rendah untuk melakukan perbaikan (Sulisworo, 2016) masih menjadi kendala besar dalam meningkatkan kualitas pendidikan di Indonesia.

\section{SIMPULAN DAN SARAN Simpulan}

Berdasarkan kajian literatur di atas, penelitian ini menyimpulkan sebagai berikut: (1) Jenis penelitian kepemipinan pendidikan di Indonseia mencakup jenis penelitian kualitatif, kuantitatif. Sedangkan penelitian mixed method 
Kelola: Jurnal Manajemen Pendidikan, Vol. 5, No. 2, Juli-Desember 2018

masih jarang dijumpai; (2) penelitian tentang jenis kepemimpinan pendidikan sudah berpijak pada teor-teori dan konsep kepemimpinan pendidikan pada aras global, namun ada beberapa jenis kepemipinan pendidikan yang merupakan khas Indonesia, seperti kepemimpinan pesantren; (2) para peneliti kepemimpinan pendidikan di Indonesia sudah mampu memahami dan mengerti berbagai indikator kepemimpinan yang efektif secara baik, antara lain kemampuan mengelola, mengorganisir, dan berkomunikasi; dan (4) para peneliti sudah memberikan rekomendasi untuk perbaikan kepemimpinan pendidikan berdasarkan hasil penelitian dengan baik, namun pendidikan Indonesia masih terus berjuang agar lebih berkualitas di tengah persaingan global yang semakin sengit.

\section{Saran}

Berdasarkan temuan di atas maka disarankan agar penelitian kepemimpinan pendidikan menggunakan jenis metode penelitian yang lebih baik seperti mixed method (penelitian bauran). Penelitian harus lebih banyak menggali kepemimpinan yang khas Indonesia, misalnya kepemimpinan pesantren dan lembaga-lembaga pendidikan agama lainnya.

\section{DAFTAR PUSTAKA}

Adams, D. 2017. Educational Leadership For The 21st Century. International Online Journal of Educational Leadership, 1(1), 1-4.

Adams, D., \& Zabidi, Z. M. 2017. Educational Leadership for the 21st Century. International Online Journal of Educational Leadership, 1(1), 1-5. https://doi.org/10.22452/iojel.vol1no1. 1

Agustina, Sulton Djasmi, I. S. 2014. Pengaruh Kepemimpinan Kepala Sekolah Iklim Kinerja Guru Terhadap Mutu Pendidikan Lampung Tengah. FKIP
Unila, Program Studi Magister Manajemen Pendidikan, 1(1), 1-15.

Amanchukwu, R. N., Stanley, G. J., \& Ololube, N. P. 2015. A Review of Leadership Theories , Principles and Styles and Their Relevance to Educational Management. Management, 5(1), 6-14. https://doi.org/10.5923/j.mm.20150501 .02

Andreas Schleicher. 2013. School Leadership for Learning. Paris: OECD Publishing, Paris.

Ansor, A. S. 2014. Manajemen Pendidikan Islam Tentang Kepemimpinan Kiai di Pondok Pesantren Tahfidz Daarul Qur'an Cipondoh Tangerang. Edukasi Islami Jurnal Pendidikan Islam, 03(Juli), 650-662.

Arifin, M. Z. 2016. Kepemimpinan Pendidikan Nabi Yusuf. Ta'allum, 04(02), 235254.

Arwin Sanjaya, A. B. 2014. Pengaruh Gaya Kepemimpinan Transformasional Terhadap Motivasi Kerja Pegawai pada Kantor Lembaga Penjaminmutu Pendidikan Provinsi Sulawesi Selatan. Ad'ministrare, 1(1), 72-83.

Ason, Y. 2013. Peranan Kepemimpinan Kepala Sekolah dan Profesionalisme Guru Dalam Implementasi Kurikulum Tingkat Satuan Pendidikan Di Sekolah Dasar. Jurnal Pendidikan Dasar, 1(1), 58-108.

Atieno, O. P. 2009. An Analysis of the Strengths And Limitation of Qualitative and Quantitative Research Paradigms. Problems Of Education In The 21st Century, 13, 13-18.

Atkinson, M. 2014. Educational leadership and management in an international school context. Kedleston Road, Derby: Un i v 
ersity of Derby Facultyof E d u c a t i o n Kedleston Road, Derby.

Bush, T. 2007. Educational leadership and management: theory, policy, and practice. South African Journal of Education, 27(3), 391-406.

Connelly, G. 2013. Leadership Matters: What the Research Says About the Importance of Principal Leadership. National Association of Elementary School Principals.

Cronin, P., Ryan, F., \& Coughlan, M. 2008. Undertaking a literatur review : a stepby-step approach. British Journal of Nursing, 17(1), 38-43.

Deki Wibowo, M. 2014. Pengaruh Gaya Kepemimpinan Kepala Sekolah dan Motivasi Berprestasi Guru Terhadap Layanan Pendidikan di Sekolah Menengah Atas. Jurnal Pendidikan Dasar, 2(2), 120-130.

Donna, W. 2011. The Importance of Educational Leadership and Policy: In Support of Effective Instruction. Center for Innovative Education and Prevention \& BrainSMART, (September).

Ekosiswoyo, R. 2007. Kepemimpinan kepala sekolah yang efektif kunci pencapaian kualitas pendidikan. Jurnal Ilmu Pendidikan, 14(2), 76-82.

Elihami. 2016. The Challenge of Religious Education in Indonesia Multiculturalism. Journal of Education and Human Development, 5(4), 211221.

https://doi.org/10.15640/jehd.v5n4a20

Evans-Curtis, M. 2004. Types of Leadership and Their Characteristics. Nova Southeastern University.
Eyal, O., \& Roth, G. 2010. Principals , leadership and teachers 'motivation. JEA, 49(3), 256-275. https://doi.org/10.1108/0957823111112 9055

Flick, U. 2013. Qualitative Data Analysis. Los Angeles/Londong/New Delhi: Sage.

Hallinger, P. 2003. Leading Educational Change : reflections on the practice of instructional and transformational leadership. Cambridge Journal of Education, 33(3), 331-350. https://doi.org/10.1080/0305764032000 122005

Hallinger, P. 2007. Research on the practice of instructional and transformational leadership: Retrospect and prospect. Research Conference, Australian Council for Educational Research, 1-7.

Hallinger, P., \& Heck, R. H. 2010. Educational Management Administration \& Leadership Leadership for Learning: Educational Management Administration \& Leadership, 38(6), 654-678. https://doi.org/10.1177/1741143210379 060

Hallinger, P., \& Huber, S. 2012. School leadership that makes a difference: international perspectives. School Effectiveness and School Improvement, 23(4), $37-41$. https://doi.org/10.1080/09243453.2012. 681508

Hallinger, P., \& Walker, A. 2017. Leading learning in Asia - emerging empirical insights from five societies. Journal of Educational Administration, 55(2), 130-146. https://doi.org/10.1108/JEA02-2017-0015

Hardiyana, A., \& Helwiyan, F. 2011. Pengaruh Kepemimpinan, Motivasi, dan 
Kelola: Jurnal Manajemen Pendidikan, Vol. 5, No. 2, Juli-Desember 2018

Lingkungan Kerja Terhadap Kinerja Pegawai Badan Kepegawaian Pendidikan dan Pelatihan Kabupaten Bandung. Jurnal Ekonomi, Bisnis \& Entrepreneurship, 5(2), 86-96.

Heck, R. H., \& Hallinger, P. 2005. The Study of Educational Leadership and Management: Where Does the Field Stand Today? Educational Management Administration \& Leadership, 33(2), 229-244. https://doi.org/10.1177/1741143205051 055

Holsted, I. 2016. School Leadership That Works. New Zealand: Education Review Office.

Inaya Rakhmani, F. S. 2016. Working Paper Series Reforming Research in Indonesia: policies and practice. GDN Working Paper, (92).

Joseph, H. P. M. 1986. Instructional Leadership in Effective Schools. The Educational Resources Information Center (ERIC), (8).

Karimah, U. 2015. Manajemen dan Kepemimpinan Pendidikan Islam. AlMurabbi, 2(Juli), 88-110.

Klette, K. 2012. Mixed Methods in Educational Research. Oslo: The Research Council of Norway.

Lemay, N., \& Ellis, A. 2008. Leadership Can Be Learned, But How Is It Measured? Management Sciences for Health, 8(8), $1-29$.

Linda Bendikson, Viviane Robinson, J. H. 2012. Principal instructional leadership and secondary school performance. Teaching and Learning, 1, 2-8.

Memon, M., Simkins, T., \& Sisum, C. 2006. Developing leadership and management capacity for school improvement.
Partnerships in Educational

Development, (January), 151-170.

Men, L. 2012. The Effects of Organizational Leadership on Strategic Internal Communication and Employee Outcomes. University of Miami.

Muhammad Saqib Khan, \& Irfanullah Khan, Qamar Afaq Qureshi, Hafiz Muhammad Ismail, Hamid Rauf, Muhammad Tahir, A. L. 2015. The Styles of Leadership : A Critical Review. Public Policy and Administration Research, 5(3), 87-93.

Nanjundeswaras, T. S., \& Swamy, D. R. 2014. Leadership styles. Advances In Management, 7(2), 57-63.

Nasution, W. N. 2015. Kepemimpinan pendidikan di sekolah. Jurnal Tarbiyah, 22(1), 6-22.

Nedelcu, A. 2013. Transformational approach to school leadership: Contribution to Continued im - provement of education. Manager, Change and Leadership, 17(17), 238-244.

Network, M. 2015. Developing Objectives And Indicators. OJ, 1(April), 1-24.

NIKOLOSKI, K. 2015. Leadership And Management: Practice of The Art of Influence. Academica Brâncuşi" Publisher, II(1), 31-39.

Nujuludin, H. D. 2013. Agama membentuk kepribadian dan gaya kepemimpinan pendidikan. Jurnal Pendidikan Universitas Garut, 07(01), 1-7.

Oh Siew Pei, C. Y. P. 2018. An Explorative Review of E-Leadership Studies. International Online Journal of Educational Leadership, 2(1), 4-20.

Peleg, S. 2012. The role of leadership in the education system. Education Journal, 1(1), 5-8. 
Pemetaan Jenis, Indikator dan Kegunaan Kepemimpinan Pendidikan ... | Rais Hidayat \& Yuyun E. Patras

https://doi.org/10.11648/j.edu.2012010 1.12

Ponce, O. A. 2015. Mixed Methods Research in Education: Capturing the Complexity of the Profession. International Journal of Educational Excellence, 1(1), 111135.

Ratnasari, S. L., \& Sutjahjo, G. 2017. Pengaruh Kepemimpinan Transformasional Dan Lingkungan Kerja Terhadap Semangat Kerja Tenaga Kependidikan. Jurnal Inspirasi Bisnis Dan Manajemen, 1(2), 99-112.

Rohmat. 2006. Kepemimpinan Pendidikan. Pemikiran, Jurnal Kependidikan, Alternatif, 11(1), 19-33.

Ruhiyat, M. Y. 2017. Pengaruh Kepemimpinan

Kepala Madrasah dan Supervisi Pengawas Madrasah terhadap Kinerja Guru untuk Mewujudkan Mutu Pendidikan di Madrasah. Jurnal Pendidikan Universitas Garut, 11(01), 26-37.

Sagala, S. 2016. Manajemen dan kepemimpinan pendidikan pondok pesantren syaiful sagala. Tarbiyah, XXII(2), 2-20.

Saiful Falah. 2015. Pendidikan Kepemimpinan M. Natsir Dan Implementasinya di Lembaga Pendidikan. Edukasi Islam Jurnal Pendidikan Islam, 04(Juli), 1076-1101.

Samuel Bazzi, Arya Gaduh, Alexander Rothenberg, M. 2017. Unity in Diversity? Ethnicity, Migration, and Nation Building in Indonesia. ResearchGate, Working Paper, (October).

Sermal. 2015. Kepemimpinan Pendidikan untuk Mengembangkan Sekolah Bermutu. Tarbiyah, XXII(2), 2-19.
Siregar, C. 2016. Pluralism and Religious Tolerance in Indonesia: An EthicalTheological Review Based on Christian Faith Perspectives. Humaniora, 7(3), 349-358.

Smith, B. S., \& Squires, V. 2016. The Role of Leadership Style in Creating a Great School. SELU Research Review Journal, 1(1), 65-78.

Soejatminah, S. 2009. Internationalisation of Indonesian Higher Education: A Study from the Periphery. Asian Social Science, 5(9), 70-78.

Spillane, J. P. 2003. Educational Leadership. Educational Evaluation and Policy Analysis, 25(4), 343-346. https://doi.org/10.3102/0162373702500 4343

Sticher, V. 2014. Indonesia: Challenges for the New Government. CSS Analyses in Security Policy, 157(July), 1-4.

Subhan, M. 2013. Kepemimpinan islami dalam peningkatan mutu lembaga pendidikan islam. Tadris, 8(1), 125-140.

Sulaiman. 2016. Kepemimpinan Kiai dalam Transformasi Pendidikan Islam ( Studi Atas Perilaku Kepemimpinan Kiai dalam Mengelola Pondok Pesantren di Situbondo ). Falasifa, 7(September 2016), 169-198.

Sulisworo, D. 2016. The Contribution of the Education System Quality to Improve the Nation' s Competitiveness of Indonesia. Journal of Education and Learning, 10(2), 127-138. https://doi.org/10.11591/edulearn.v10i2 .3468

Sumarsono, R. B. 2012. Hubungan perilaku kepemimpinan kepala sekolah dan kemampuan mengajar guru dengan inovasi pendidikan. Jurnal Manajemen Pendidikan, VIII(01), 23-39. 
Kelola: Jurnal Manajemen Pendidikan, Vol. 5, No. 2, Juli-Desember 2018

Sumintono, R. and B. 2010. Teacher education in Indonesia: development and challenges. International Handbook of Teacher Education World-Wide, (May 2014), 181-197.

Suratno, T. 2016. The education system in Indonesia at a time of significant changes. Revue Internationale d'éducation de Sèvres, (September).

Susanthi, N. I., \& Setiawan, A. 2014. The Effect of Leadership Style on Motivation to Improve the Employee Performance. Jurnal Manajemen Transportasi \& Logistik (JMTransLog), 01(03), 221-226.

Suter, S. 2015. Goals , Targets and Indicators Defining and Prioritizing Targets Potential criteria for targets in the post2015 development agenda. Independent Research Forum, 2.

Tumonggor, M. K., Karafet, T. M., Hallmark, B., Lansing, J. S., Sudoyo, H., Hammer, M. F., \& Cox, M. P. 2013. The Indonesian archipelago: an ancient genetic highway linking Asia and the Pacific. Journal of Human Genetics, 58(3), $165-173$. https://doi.org/10.1038/jhg.2012.154

Urick, A., \& Bowers, A. J. 2014. What Are the Different Types of Principals Across the United States? A Latent Class Analysis of Principal Perception of Leadership. Educational Administration Quarterly, 50(1), 96-134. https://doi.org/10.1177/0013161X1348 9019

Usman, H. 2013. Kepemimpinan Berkarakter Sebagai Model Pendidikan Karakter. Jurnal Pendidikan Karakter, III(3), 265-273.
Velarde, J. 2017. Instructional Leadership Practices In International Schools International Online Journal of Educational, 1(1), 90-117.

Veliu, L., Manxhari, M., Demiri, V., \& Jahaj, L. 2017. The Influence Of Leadership Styles on Employee's Performance. Vadyba Journal of Management, 31(2), 59-69.

Wahyudi, H. R. 2014. Pengaruh Kepemimpinan Transformasional Kepala Sekolah, Pelaksanaan MBS, Dan Pelaksanaan TU Terhadap Kualitas Pendidikan SD/MI Depok Sleman. Jurnal Akuntabilitas Manajemen Pendidikan, 2, 250-264.

Walukow, Donald M. F. Tiogas, A. F. 2014. Pengaruh Kepemimpinan Kepala Sekolah, Supervisi dan Kepuasan Kerja Guru Terhadap Kinerja Guru Mipa Di Yayasan Pendidikan Advent Timika. Jurnal Ilmu Pendidikan Indonesia, 2(November 3), 41-51.

Yahya, S. A. 2015. Leadership Styles, Types and Students' Academic Achievement In Nigeria. Universiti Tun Hussein Onn Malaysia.

Yusuf, M. 2014. Multikulturalime dan Kepemimpinan Pendidikan Islam. Jurnal Kepemimpinan Pendidikan Islam Multikultural, 2(1), 122-139.

Zakeer Ahmed Khan, Allah Nawaz, I. K. 2016. Leadership Theories and Styles: A Literatur Review. Journal of Resources Development and Management, 16(January), 1-8.

Zuhdi, M. 2015. Religious Education in Indonesian Schools. Singapore. 